\title{
Síndrome de Miller Fisher y polineuritis craneal como manifestación de COVID-19
}

\author{
Miller Fisher syndrome and polyneuritis \\ cranialis as manifestation of COVID-19
}

\author{
José Luis Alcocer Maldonado, ${ }^{*}$ Luis Gerardo Domínguez Carrillo ${ }^{\ddagger}$ \\ Citar como: Alcocer MJL, Domínguez CLG. Síndrome de Miller Fisher y polineuritis craneal como manifestación \\ de COVID-19. Acta Med Grupo Angeles. 2021; 19 (3): 368-371. https://dx.doi.org/10.35366/101729
}

\section{Resumen}

Introducción: La pandemia de SARS-CoV-2 ha ocasionado una avalancha de información sobre la afectación de diferentes sistemas, incluyendo al sistema nervioso central y periférico. Objetivo: Informar el primer caso en la localidad con síndrome respiratorio agudo por SARS-CoV-2 que presentó de forma aguda el síndrome de Miller Fisher y diplejía facial. Caso clínico: Mujer de 46 años que presentó anosmia, ageusia, oftalmoparesia derecha inicialmente, pasando a oftalmoplejía bilateral, discreta ataxia, arreflexia, diplejía facial, disfagia moderada, disociación albúmino-citológica en líquido cefalorraquídeo (LCR) y prueba positiva de anticuerpos GD1b-IgG. Cinco días antes, había desarrollado tos, malestar general, dolor de cabeza y fatiga. La prueba de frotis orofaríngeo para COVID-19 mediante el ensayo cualitativo de reacción en cadena de la polimerasa con transcriptasa inversa en tiempo real fue positiva, siendo negativa en LCR. Manejada con inmunoglobulina intravenosa y acetaminofén. Dos semanas después de su alta, fue derivada a rehabilitación para manejo fisiátrico de la diplejía facial. Conclusiones: Se reporta el primer caso en León, Guanajuato, México de síndrome de Miller Fisher y polineuritis craneal durante la pandemia de COVID-19. Las manifestaciones neurológicas pueden ocurrir debido a una respuesta inmune aberrante al COVID-19.

Palabras clave: Síndrome de Miller Fisher, polineuritis craneal, diplejía facial, COVID-19.

\footnotetext{
* Neurocirujano. División de Cirugía del Hospital Ángeles León, León, Guanajuato. México.

* Especialista en Medicina de Rehabilitación. Catedrático de la Facultad de Medicina de la Universidad de Guanajuato, Campus León. México.
}

Correspondencia:

Dr. Luis Gerardo Domínguez Carrillo

Correo electrónico: Igdominguez@hotmail.com

Aceptado: 29-08-2020.

www.medigraphic.com/actamedica

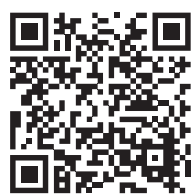

\section{Abstract}

Introduction: The SARS-CoV-2 pandemic has caused an avalanche of information about the affectation of different systems including the central and peripheral nervous systems. Objective: Report the first case in the locality with acute respiratory syndrome due to SARS-CoV-2 that acutely presented Miller Fisher syndrome and facial diplegia. Clinical case: 46-year-old female who initially presented anosmia, ageusia, right ophthalmoparesis, passing to bilateral ophthalmoplegia, mild ataxia, areflexia, facial diplegia, moderate dysphagia, albumine-cytological dissociation in CSF and positive test for GD1b-IgG antibodies. Five days earlier, she had developed a cough, malaise, headache, and fatigue. The oropharyngeal smear test for (COVID-19) by the qualitative real-time reverse transcriptase polymerase chain reaction assay was positive, being negative in CSF. Managed with intravenous immunoglobulin and acetaminophen. Two weeks after discharge, she was referred to rehabilitation for the physical management of facial diplegia. Conclusions: The first case of Miller Fisher syndrome and cranial polyneuritis during the COVID-19 pandemic is reported in Leon, Guanajuato, Mexico. Neurological manifestations can occur due to an aberrant immune response to COVID-19.

Keywords: Miller Fisher syndrome, cranial polyneuritis, facial diplegia, COVID-19. 
anosmia, ageusia, mialgias y mareo; otras afectaciones neurológicas descritas son encefalopatía, incremento del riesgo de ictus, polineuropatía y mononeuritis. ${ }^{2}$ Respecto a afecciones de nervios periféricos relacionadas con infección por COVID-19, parece estar implicada una respuesta inflamatoria desencadenada por la presencia de virus, lo cual podría conllevar que la fisiopatogenia se relaciona con mecanismos inmunológicos capaces de producir daño al nervio. La relación de afecciones del sistema nervioso central y periférico con los virus, en especial con los coronavirus, no es nueva, los miembros de la familia Coronaviridae, en particular del género $\beta$ como el caso de los virus del síndrome respiratorio agudo severo (SARS-CoV-1) ${ }^{3}$ en 2002-2003, originaron reportes sobre pacientes con polineuropatía, enfermedad cerebrovascular isquémica y encefalitis; por otro lado, el síndrome respiratorio del Medio Oriente $\left(\right.$ MERS-CoV) ${ }^{4}$ en 2009 dio pie a los reportes de casos con polineuropatía, parálisis, convulsiones, alteraciones de la conciencia. El síndrome de Miller Fisher ${ }^{5}$ es una variante del de Guillain-Barré, se caracteriza por oftalmoplejía, arreflexia y ataxia, se reconoció por primera vez como una entidad clínica distinta en 1956 y su incidencia es de 0.09 por 100,000 habitantes. ${ }^{4}$ Una infección viral precede a los síntomas neurológicos en $72 \%$ de los casos, afectando más al género masculino; la edad promedio de aparición es a los 40 años con variación de 13 a 78 años, ${ }^{6}$ el cuadro clínico se desarrolla entre los 10 a 14 días después de la infección, la afección a otros nervios craneales se encuentra en 40 a $57 \%$ y la asistencia mecánica ventilatoria es rara. Presentamos este artículo porque, hasta donde tenemos información, es el primer caso con diagnóstico de síndrome de Miller Fisher relacionado con SARS-CoV-2 en la ciudad de León, Guanajuato, México.

\section{CASO CLÍNICO}

Mujer de 46 años que inició con evacuaciones diarreicas cinco días antes de su llegada a urgencias, agregándose: tos seca, malestar general, dolor de cabeza, fatiga, ageusia y anosmia; un día antes de su ingreso, notó dificultad para elevar párpado derecho (Figura 1A), incremento de la intensidad de cefalea y fatiga muscular a la masticación, 12 horas después presentó diplopía e imposibilidad para gesticulación facial bilateral y discreta ataxia, por lo que acude a urgencias, fue valorada y hospitalizada por Neurocirugía con diagnóstico de síndrome de Miller Fisher, por presentar a la exploración de pares craneales anosmia por afección de I par, II par normal (no edema de papila visión 20/20), oftalmoplejía bilateral, más severa derecha con afección de III par (Figura 1B), con pupilas midriáticas y pobre respuesta a la luz bilateral, así como paresia de IV y VI pares craneales, fuerza muscular disminuida a $3 / 5$ en músculos maseteros y temporales por afección de $\mathrm{V}$ par, no existiendo cambios en sensibilidad facial; diplejía facial periférica por afección del VII par (Figura 1B), discreta ataxia y desviación en la marcha a la derecha y Romberg positivo por afección del VIII par, sin náusea ni vómito, ageusia por afección de VII y IX pares craneales, disfagia discreta pudiendo pasar líquidos, paladar sin alteraciones, con cambios en tono de la voz por alteración discreta del $X$ par, pero con cuerdas con movimientos normales, pares craneales XI y XII normales. La paciente presentó a su ingreso FC de $90 \mathrm{lat} / \mathrm{min}$; TA 100/60 mmHg; FR 18 resp/min; temperatura $36.8{ }^{\circ} \mathrm{C}$; peso de $56 \mathrm{~kg}$; talla 160 $\mathrm{cm}$; índice de masa corporal (IMC) de 21.9. El resto de la exploración resultó normal. Se efectuó punción lumbar para extracción de líquido cefalorraquídeo (LCR), además se efectuó prueba oro y nasofaríngea para COVID-19 mediante el ensayo cualitativo de reacción en cadena de la polimerasa con transcriptasa inversa en tiempo real, con resultado positivo, identificando a los genes $L$, E y RDRT que corresponden al virus COVID-19, el cual mostró disociación albúmino-citológica en LCR con proteínas de 580 $\mathrm{mg} / \mathrm{dL}$ y 4 mononucleares $/ \mathrm{mm}^{3}$ y glucosa de $70 \mathrm{mg} / \mathrm{dL}$; se reportaron anticuerpos GD1b-IgG y anti-GQ1b positivos, la prueba PCR para COVID-19 en LCR resultó negativa, la resonancia magnética de encéfalo con resultados normales. Se le manejó con inmunoglobulina (Ig) IV a dosis de $0.4 \mathrm{~g} /$ kg/día (20.8 g) divididos en dos dosis/día, utilizando en total 13 aplicaciones y paracetamol logrando detener el avance del problema. La paciente permaneció hospitalizada por seis días y fue derivada a rehabilitación a los 14 días, al momento de escribir este reporte tiene seis sesiones en fisioterapia aún sin cambios.

\section{DISCUSIÓN}

El síndrome de Miller Fisher, ${ }^{6}$ descrito en 1956 como entidad clínica, es una enfermedad aguda paralítica autoinmune desmielinizante causada por la afección de los nervios craneales y periféricos, considerado como una variedad de presentación clínica del síndrome de Guillain-Barré. La tríada clásica se caracteriza por oftalmoplejía, arreflexia y ataxia. El antecedente de un cuadro infeccioso precede a los síntomas en 43 a $60 \%$ de los casos, se le ha relacionado a Campylobacter jejuni (21\%), Haemophilus influenzae (8\%), Citomegalovirus (3\%) y Mycoplasma pneumoniae (3\%). En más de $90 \%$ de los pacientes con síndrome de Miller Fisher (SMF) se detectan anticuerpos anti-GQ1b y los títulos de lgG son mayores al inicio del cuadro. Histopatológicamente se observa desmielinización e infiltración mononuclear de los nervios. La instauración del cuadro suele ser aguda en horas o días, esta última es la que se reporta con más frecuencia. En su evolución, la oftalmoplejía, ataxia, arreflexia y blefaroptosis se presenta en 35\%, parálisis 


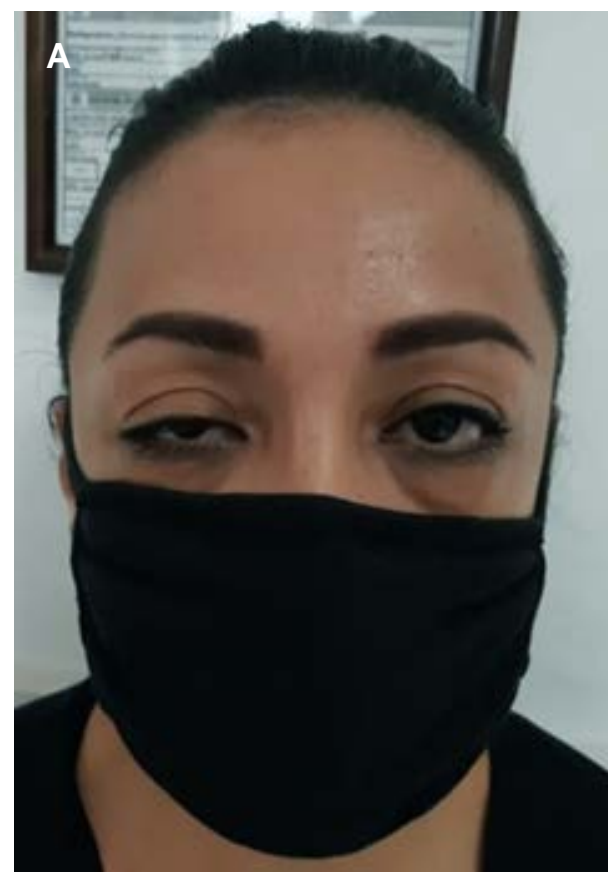

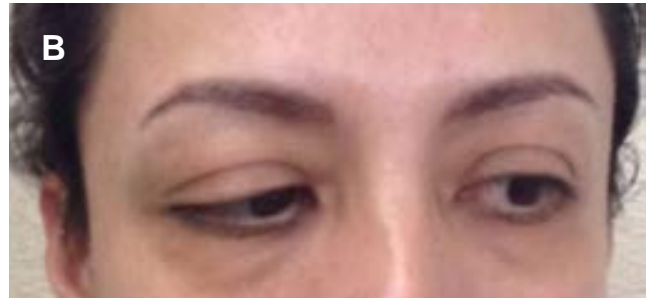
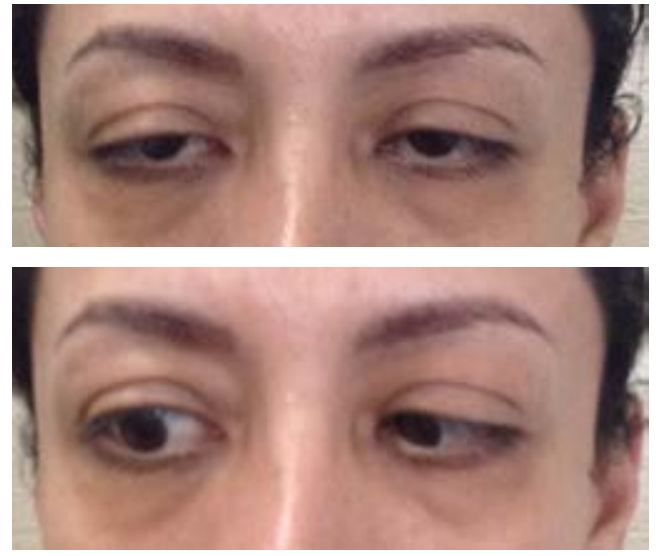

Figura 1:

Fotografías clínicas: A) Un día antes de su ingreso (fotografía tomada por el esposo), con dificultad para elevar párpado superior aún sin diplopía. B) 24 horas después, al momento de su ingreso con oftalmoplejía y diplopía. facial en 35\%, afección bulbar en 16\% y la alteración sensitiva en $52 \%$. ${ }^{7}$ El análisis del líquido cefalorraquídeo puede mostrar una disociación citológica-albúmina, aunque al inicio puede ser normal, lo que concuerda con los hallazgos previamente reportados. Los estudios de conducción nerviosa demuestran la afección desmielinizante. El diagnóstico diferencial incluye la encefalitis de Bickerstaff, esclerosis múltiple, síndrome de Tolosa-Hunt, síndromes paraneoplásicos, entre otros. La COrrelación de la tríada de oftalmoplejía, arreflexia y ataxia con los títulos positivos de los anticuerpos anti-GQ1b confirma su especificidad para el diagnóstico de SMF. El tratamiento con IgG IV y plasmaféresis han demostrado utilidad en estudios aleatorizados, doble ciego comparativos con placebo. En adultos se observa una buena respuesta al tratamiento en dos tercios de los pacientes, la cual inicia dentro de las dos semanas posteriores a la aparición de los síntomas y las funciones se recuperan completamente de los tres a los cinco meses siguientes. En nuestros pacientes no se tienen estudios de detección de anticuerpos, pero se presentó una adecuada respuesta al tratamiento con inmunoglobulina, logrando estabilizar y detener el avance de la enfermedad. ${ }^{8,9}$ En cuanto al pronóstico el tiempo promedio de recuperación tanto de Guillain Barré como del síndrome de Miller Fisher, oscila entre las ocho y 12 semanas; sin embargo, puede prolongarse hasta 12 meses, con posibilidades de síntomas residuales y secuelas, además se ha informado de casos con recurrencias. ${ }^{10}$

La aparición a fines del 2019 del SARS-CoV-2 ha originado una verdadera avalancha de información, no sólo de afección pulmonar, sino de otros aparatos y sistemas, entre ellos el sistema nervioso central (SNC) y periférico (SNP); como ejemplo, en el presente año, Mao ${ }^{11}$ y colaboradores en Wuhan (origen geográfico de la pandemia), describieron un grupo de 214 pacientes hospitalizados con SARS-CoV-2, del cual $36.4 \%$ presentó alguna manifestación neurológica clasificada como afectación central (24.8\%), periférica (10.7\%) o musculoesquelética (10.7\%). El primer caso de síndrome de Guillain-Barré relacionado directamente con SARS-CoV-2 fue reportado por Zhao ${ }^{12}$ y su equipo, por otra parte, Toscano $^{13}$ y su grupo en Italia reportaron cinco pacientes con síndrome de Guillain-Barré como complicación neurológica de infección por SARS-CoV-2 con un intervalo desde los síntomas respiratorios hasta los síntomas del síndrome de 5-10 días; los dos primeros casos de síndrome de Miller Fisher y polineuritis craneal relacionados con SARS-CoV-2 fueron reportados por Gutiérrez ${ }^{14}$ y colaboradores en España, mientras que el primer caso de oftalmoparesia asociado con parálisis facial lo reporta Dinkin ${ }^{7}$ y su grupo en los Estados Unidos de América. Respecto a los dos pacientes con manifestaciones clínicas de afectación del SNP por COVID-19, el primero era un hombre de 50 años con antecedentes de dos días de fiebre, diplopía vertical, parestesias periorales, anosmia, ageusia e inestabilidad, marcha atáxica amplia y arreflexia global; al examen neuroftalmológico mostró hipertropía derecha en todos los campos de la mirada, limitación severa de la aducción y los movimientos de la mirada hacia abajo del ojo derecho, además de nistagmo del ojo izquierdo compatible con oftalmoparesia internuclear derecha y parálisis oculomotora fascicular derecha. El 
anticuerpo antigangliósido GD1b-lgG fue positivo al igual que la prueba de SARS-CoV-2. El LCR no mostró células y una proteína de $80 \mathrm{mg} / \mathrm{dL}$. CSF-RT-PCR fue negativo para COVID-19. Se le diagnosticó síndrome de Miller Fisher (oftalmoplejía externa, ataxia y arreflexia) y polineuropatía craneal con buena respuesta a Ig IV. ${ }^{15}$

En cuanto a la fisiopatogenia, las descripciones de infección pulmonar por coronavirus humano han mostrado incremento de exudado inflamatorio alveolar e intersticial, causando hipoxia que induce el metabolismo anaerobio; además, se origina la denominada tormenta de citosinas, ${ }^{16}$ que se caracteriza por una liberación excesiva de factores proinflamatorios de interleucinas (IL-6, IL-12, IL-15) y factor de necrosis tumoral $\alpha$, reacción que parece ser común en varios de los coronavirus, especialmente SARS-CoV- $2 .{ }^{17}$ Además, estudios en cultivos celulares in vitro identificaron que las células gliales, después de ser infectadas por los coronavirus, también expresan incremento de estos factores mencionados; por otra parte, se han confirmado partículas virales en neuronas cerebrales de ratones, lo que puede explicar el compromiso neurológico del SARS-CoV-2, ya que en neuronas y células gliales existe alta expresión de receptores de la enzima convertidora de angiotensina 2 (ECA-2). ${ }^{18}$

Los cambios neuropatológicos reportados por $\mathrm{Wu}^{19} \mathrm{y}$ colaboradores en cerebros de cadáveres que fallecieron por SARS-CoV-2 incluyeron degeneración y necrosis de neuronas, hiperplasia extensa de células gliales e infiltrados celulares, pero sin desmielinización. La inmunotinción mostró una monoquina inducida por interferón- $\gamma$ (Mig) en células gliales e infiltración de monocitos, macrófagos CD68 positivos y linfocitos T CD3 positivos en el parénquima cerebral, además de elevados niveles sanguíneos de proteína 10 inducible por interferón- $\gamma$ y Mig en sangre.

\section{CONCLUSIÓN}

Es importante destacar y conocer las diferentes manifestaciones del virus causante de la pandemia actual. En este reporte comunicamos hasta donde tenemos información del primer caso de síndrome de Miller Fisher asociado con polineuritis craneal en asociación con COVID-19 en León, Guanajuato, México.

\section{REFERENCIAS}

1. Dubé M, Le Coupanec A, Wong AHM, Rini JM, Desforges M, Talbot PJ. Axonal transport enables neuron-to-neuron propagation of human coronavirus OC43. J Virol. 2018; 92 (17): e00404-18.
2. Carod-Artal FJ. Complicaciones neurológicas por coronavirus y COVID-19. Rev Neurol. 2020; 70: 311-322.

3. Chao CC, Tsai LK, Chiou YH, Tseng MT, Hsieh ST, Chang SC et al. Peripheral nerve disease in SARS: report of a case. Neurology. 2003; 61 (12): 1820-1821.

4. Stainsby B, Howitt S, Porr J. Neuromusculoskeletal disorders following SARS: a case series. J Can Chiropr Assoc. 2011; 55 (1): 32-39.

5. Rodríguez UJ, Delgado LF, Franco ME, Bernal SM, Martínez CQ, Palomino AG. Síndrome de Miller-Fisher: hallazgos clínicos, infecciones asociadas y evolución en 8 pacientes. Med Clin. 2004; 122 (6): 223-226

6. Fisher M. An unusual variant of acute idiopathic polyneuritis (syndrome of ophthalmoplegia, ataxia and areflexia). N Engl J Med. 1956; 255 (2): 57-65.

7. Dinkin M, Gao V, Kahan J, Bobker S, Simonetto M, Wechsler P et al. COVID-19 presenting with ophthalmoparesis from cranial nerve palsy. Neurology. 2020; 95 (5): 221-223.

8. Santos ME, Cabrera AE, Gudiño FE, Jiménez HM, Hernández BR, Hernández BR et al. Síndrome de Miller Fisher. Arch Neurocien (Mex). 2007; 12 (3): 180-182.

9. Zaldívar RJM, Sosa HJ, García TD, Guillén CAM, Pérez AOL. Síndrome de Miller Fisher. A propósito de un caso. Rev Ciencias Médicas. 2011; 15 (2): 261-268.

10. Wang Y, Lang W, Zhang Y, Ma X, Zhou C, Zhang HL. Long-term prognosis of Guillain-Barré syndrome not determined by treatment options? Oncotarget. 2017; 8 (45): 79991-80001. doi: 10.18632/ oncotarget.20620.

11. Mao L, Wang M, Chen S, He Q, Chang J, Hong C et al. Neurological manifestations of hospitalized patients with COVID-19 in Wuhan, China: a retrospective case series study. MedRxiv. 2020. doi: 10.1101/2020.02.22.20026500.

12. Zhao H, Shen D, Zhou H, Liu J, Chen S. Guillain-Barré syndrome associated with SARS-CoV-2 infection: causality or coincidence? Lancet Neurol. 2020; 19 (5): 383-384.

13. Toscano G, Palmerini F, Ravaglia S, Ruiz L, Invernizzi P, Cuzzoni MG et al. Guillain-Barré syndrome associated with SARS-CoV-2. N Engl J Med. 2020; 382 (26): 2574-2576. doi: 10.1056/NEJMc2009191.

14. Gutiérrez-Ortiz C, Méndez-Guerrero A, Rodrigo-Rey S, San PedroMurillo E, Bermejo-Guerrero L, Gordo-Mañas R et al. Miller Fisher syndrome and polyneuritis cranialis in COVID-19. Neurology. 2020; 95 (5): e601-e605. doi: 10.1212/WNL.0000000000009619.

15. Román GC, Spencer PS, Reis J, Buguet A, Faris MEA, Katrak SM et al. The neurology of COVID-19 revisited: A proposal from the Environmental Neurology Specialty Group of the World Federation of Neurology to implement international neurological registries. J Neurol Sci. 2020; 414: 116884.

16. Rothan HA, Byrareddy SN. The epidemiology and pathogenesis of coronavirus disease (COVID-19) outbreak. J Autoimmun. 2020; 109: 102433.

17. Li YC, Bai WZ, Hashikawa T. The neuroinvasive potential of SARSCoV2 may play a role in the respiratory failure of COVID-19 patients. J Med Virol. 2020; 92 (6): 552-555. doi: 10.1002/jmv.25728.

18. Orozco-Hernández JP, Marin-Medina DS, Sánchez-Duque JA. Neurological manifestations of SARS-CoV-2 infection. Semergen. 2020; 46 Suppl 1: 106-108. doi: 10.1016/j.semerg.2020.05.004.

19. Wu Y, Xu X, Chen Z, Duan J, Hashimoto K, Yang L et al. Nervous system involvement after infection with COVID-19 and other coronaviruses. Brain Behav Immun. 2020; 87: 18-22. doi: 10.1016/j. bbi.2020.03.031. 